\title{
Review of Therapeutic Options for Spinal Muscular Atrophy
}

\author{
Arun Singh, ${ }^{1}$ Monica Jain, ${ }^{1}$ Rupa Kapadia, ${ }^{1}$ Dhirendra Kumar Mahawar, \\ Shivankan Kakkar, ${ }^{1}$ Jaya Dadhich, ${ }^{1}$ Ritesh Kumar Chandel'
}

\begin{abstract}
Spinal Muscular Atrophy (SMA) is uncommon genetic (autosomal recessive) disease that deteriorates neuromuscular function of the affected person's body by causing lower motor neuron damage, progress in muscle atrophy and in advanced cases leads to paralysis of muscles. Mainly skeletal and respiratory muscles are involved. SMA is present due to lack of SMA proteins, which are encoded by survival motor neuron-1 (SMN-1) genes. In mutation of SMN-1 genes, deficiency of SMN proteins occurs. SMA affects all age groups, but mainly and most severely children younger than 6 months of age. At present, risdiplam is a treatment option and the drug has been approved by the US Food Drug and Administration on 7 August 2020. The availability of the drug has led to increased financial, ethical and medical problems. SMA affected populations are regularly challenged to these issues.
\end{abstract}

Key words: Spinal muscular atrophy; SMN-1; Rare disease frequency; Therapeutic approaches; Risdiplam; Nusinersen; Onasemnogene abeparvovec.
(1) Department of Pharmacology, SMS Medical College and Hospital, Jaipur, India.

Correspondence:

ARUN SIGH

E: aruns5130@gmail.com

\section{ARTICLE INFO}

Received: 27 March 2021

Revision received: 12 May 2021 Accepted: 12 May 2021

\section{Introduction}

Spinal muscular atrophy (SMA) is cluster of hereditary disorders with both copies of the gene mutated. This kind of disorders are usually passed on by 2 carriers. Carrier's health is generally not affected, except in rare cases. SMA is depicted by degeneration of alpha motor neurons within spinal cord. Muscles atrophy gradually progress, which is manifested as muscle weakness that progress into paralysis. ${ }^{1}$ SMA disease was first defined in 1980 by a German scientist Johann Hoffman and an Australian scientist Guido Werdning. Both scientists had observed many cases of children developing muscle weakness during the first few months of life. They also have seen that this illness appeared in next generations, but only in some members. ${ }^{1,2}$ SMA occurs due to bi-allelic point mutations of the SMN-1 gene, leading to de- generation of $\alpha$-motor neurons in spinal cord. The presentation of this disease varies and depends upon disease starts and severity form. Crawling, sit up, walk or mobility of head is affected in children with SMA. In most severe cases of SMA, it can diminish the respiratory muscles and muscles used for swallowing.

\section{Epidemiology}

SMA is the second most typical rare autosomal recessive disease in Indian populations after incidence of cystic fibrosis. The global incidence of SMA is frequently cited as being approximated one in 10,000-11,000 live births. ${ }^{3}$ The carrier fre- 
quency of SMA is as high as one in forty to one in sixty. ${ }^{4,5}$ Why SMA disease is considered as a rare disease? In order for something to be considered a rare disease it is necessary to consider 3 parameters:

1. The entire range of individuals having the disease

2. Its prevalence in population

3. Non-available treatment for this disorder.

Organisation for Rare Diseases in India (ORDI) recommends a disease to be well-defined as rare if the disease affects one in 5,000 population or less. But according to the suggestion of World Health Organisation, rare disease should be one with frequency less than $6.5-10$ per 10,000 people.

Table 1 : Population based frequency of rare disease (according to CIOMS)

\begin{tabular}{ll}
\hline Rare disease frequency & In total population \\
\hline Very common & $\begin{array}{l}\text { Equivalent one or more than one out of ten } \\
(\geq 10 \%)\end{array}$ \\
\hline Common, frequent & $\begin{array}{l}\text { Equivalent one or more than one out of hundred } \\
\text { and less than one out of ten }(\geq 1 \% \text { and }<10 \%)\end{array}$ \\
Encommon, infrequent & $\begin{array}{l}\text { Equivalent one or more than one out of } \\
\text { thousand and less than one out of hundred } \\
(\geq 0.1 \% \text { and }<1 \%)\end{array}$ \\
Rare & $\begin{array}{l}\text { Equivalent one or more than one out of ten } \\
\text { thousand less than one out of thousand } \\
(\geq 0.01 \% \text { and }<0.1 \%)\end{array}$ \\
Very rare & Less than one out of ten thousand $(<0.01 \%)$ \\
\hline
\end{tabular}

SMA is considered as rare disease because it affects one in 5,000-8,000 of population in India. The medications used for treating SMA are called orphan drugs. An orphan drug is a pharmaceutical agent developed to treat medical conditions which, because they are so rare, would not be profitable to produce without government assistance.

\section{Causes of SMA}

The consequence of mutation in the SMN-1 gene, located on chromosome 5 , is a lack of a motor neuron protein. The total number of copies of the SMN-2 gene alters the severity of SMA disease. There are two SMN-1 genes in population. In $94 \%$ of all SMA cases, mutation involves a deletion of end of exon 7. The definite place of mutation is chromosome number five's q-arm, in the 5q13.2 region.
Normally, SMN-1 genes give outcome as full-length size and fully functional SMN protein. In spite of this, whenever the mutations occur in SMN-1 gene, it results SMA's chromosome number five form. Insufficient levels of SMN protein are formed in this SMN-1 gene. The other, SMN-2 gene that is located on chromosome five, also produces SMN proteins. The SMN-2 genes mostly produce proteins that carry commands which are non-functional. Apart from this non-functional protein, a small proportion of protein made from SMN-2 gene, approximately 10 to $15 \%$ is functional.

The continuous reduction in the SMN protein produces lower motor neuron degeneration as result and progress into muscle atrophy and finally muscle paralysis. In SMA, mainly respiratory and skeletal muscles are involved. Patients mainly have difficulties in breathing and they are unable to sit and walk independently.

\section{Classification of SMA}

SMA is categorised into five subtypes (including 0 type). This categorisation depends upon age at onset of disease and maximum motor neuron activity execute (Table 2 ). ${ }^{6}$

Table 2 : Classification criteria for SMA on the basis of its clinical features

\begin{tabular}{|c|c|c|c|}
\hline Types & Also known as & Onset & $\begin{array}{l}\text { Achieved development } \\
\text { milestones }\end{array}$ \\
\hline 0 & - & Before birth & Cannot survive \\
\hline I & $\begin{array}{l}\text { Werdnig-Hoffmann } \\
\text { disease; infantile }\end{array}$ & $0-6$ months & Never achieve sitting \\
\hline$\|$ & $\begin{array}{l}\text { Dubowitz disease; } \\
\text { intermediate type }\end{array}$ & $\begin{array}{l}\text { In between } 7 \\
\text { to } 18 \text { months }\end{array}$ & Sitting, never achieve standing \\
\hline III & $\begin{array}{l}\text { Kugelberg-Welander } \\
\text { disease; mild; adult }\end{array}$ & $\begin{array}{l}\text { In between } \\
18 \text { months } \\
\text { to } 35 \text { years }\end{array}$ & $\begin{array}{l}\text { Stand and walk throughout } \\
\text { adulthood }\end{array}$ \\
\hline IV & Adult & $>35$ years & Walk unaided \\
\hline
\end{tabular}

SMA-0 type is a rarest form of SMA. Symptoms of SMA-0 become apparent as reduced movements of foetus during intrauterine life. The affected newborn characteristically has only 1 copy of SMN-2 gene and generally the they survive only a few weeks even with intensive respiratory support.

SMA-I type (also known as Werdnig-Hoffmann disease) is a very serious disease that typically appears around six months of age. A baby may be born with respiratory symptoms that can be 
threatening within a year if the child is not treated. These patients also have decreased muscle tone, severe and progressive muscle weakness, abnormal swallowing and speech, weakened suckling capacity and respiratory failure. A gynaecologist observes the SMA-I type during intrauterine life. During the last months of gestation less movement of the foetus are found. ${ }^{7}$ If not found in last months of pregnancy, it will become evident within the first few months of baby's life after birth. With these types of SMA disease babies have multiple risks of aspiration and they are unable to thrive. SMA-I is characterised in rapid motor neuron loss. It results in death or permanent ventilator support in $>90 \%$ of patients. Patients suffering from SMA-I usually have 2 or 3 copies of the SMN-2 gene. ${ }^{8}$

SMA-II or Dubowitz disease or intermediate type features usually onset between 6 and 18 months of life. Patients accomplish the strength to take a seat without support and in few of them, acquire ability to stand, however do not acquire the ability to walk independently. SMA-II patients are characterised by problems of sitting without support or they fail to stand till one year. They develop pseudohypertrophy of the calf muscle and musculoskeletal deformity. Respiratory failure can also happen, and patient can live only with ventilatory support. SMA-II affected children mostly have 3 copies of the SMN-2 gene. ${ }^{9}$ They have predominantly proximal muscle weakness. Proximal muscles of lower extremities are mainly involved. Facial muscles or ocular muscles remain unaffected. ${ }^{8}$

SMA-III, mild-SMA, also known as Kugelberg-Welander disease is characterised by different levels of muscle weakness. SMA-III patients have 3-4 copies of the SMN-2 gene. SMA-III (juvenile onset) incidence is $30 \%$ of overall SMA cases in population. Affected individuals walk without support. In these patients, weakness of proximal muscles would lead to frequent falls and issue with climbing stairs. Over time, a loss of the ability to stand and walk occurs.

SMA-IV is present in later life and incidence is less than $5 \%$ of overall SMA patients. ${ }^{9}$ In this type SMA, patients have 4-8 copies of the SMN2 gene. ${ }^{8}$ Age of onset is uncertain but it usually occurs later, at thirty years of age. SMA-IV is an insignificant form of SMA and consequently patient's life expectancy remains normal. They achieve motor milestones and maintain mobility throughout life.
Developmental milestone and diseases severity progression is generally analysed by using authenticated purposeful scales - The Children's Hospital of Philadelphia Infant Test of Neuromuscular Disorders (CHOP-INTEND) / Hammersmith Infant Neurological Examination (HINE) in babies; and either the Motor Function Measure (MFM) or one of some variants of the Hammersmith Functional Motor Scale (HFMS) in elderly cases are used.

\section{Diagnosis of SMA}

Early assessment of SMA is likely during pregnancy by detection of foetal movements. In such patients, there are reduced and absent foetal movements in the intrauterine life. Respiratory distress and poor feeding are life-threatening. It takes only a few weeks for death. SMA disease is definitively confirmed by genetic testing methods. The disease progression (muscle atrophy) is detected by a muscle biopsy.

\section{Therapeutic options for SMA}

The therapeutic options for SMA vary from case to case. They are based upon the disease type and severity. Most severe SMA type (SMA types 0 / I), has extreme muscle atrophy and weakness necessitating rapid therapeutics. In less severe type (type-IV) intervention may not be necessary in childhood, until forthcoming life decades.

The SMA disease's pathophysiology is incompletely understood till now. Nevertheless, various growths in understanding to the molecular basis theory of this kind of rare disease has been done and different therapeutics are evolving over the past years. ${ }^{14}$ On December 2016, the first approved drug for SMA disease was nusinersen (trade name - Spinraza) by the US Food and Drug Administration (FDA). It is administrated in SMA patients by intrathecal route. Later on, the first oral drug for SMA was discovered. The name of this drug was risdiplam (trade name - Evrysdi) which was approved by FDA for the treatment of SMA disease in adults and children aged two months and older on 7 August 2020. 


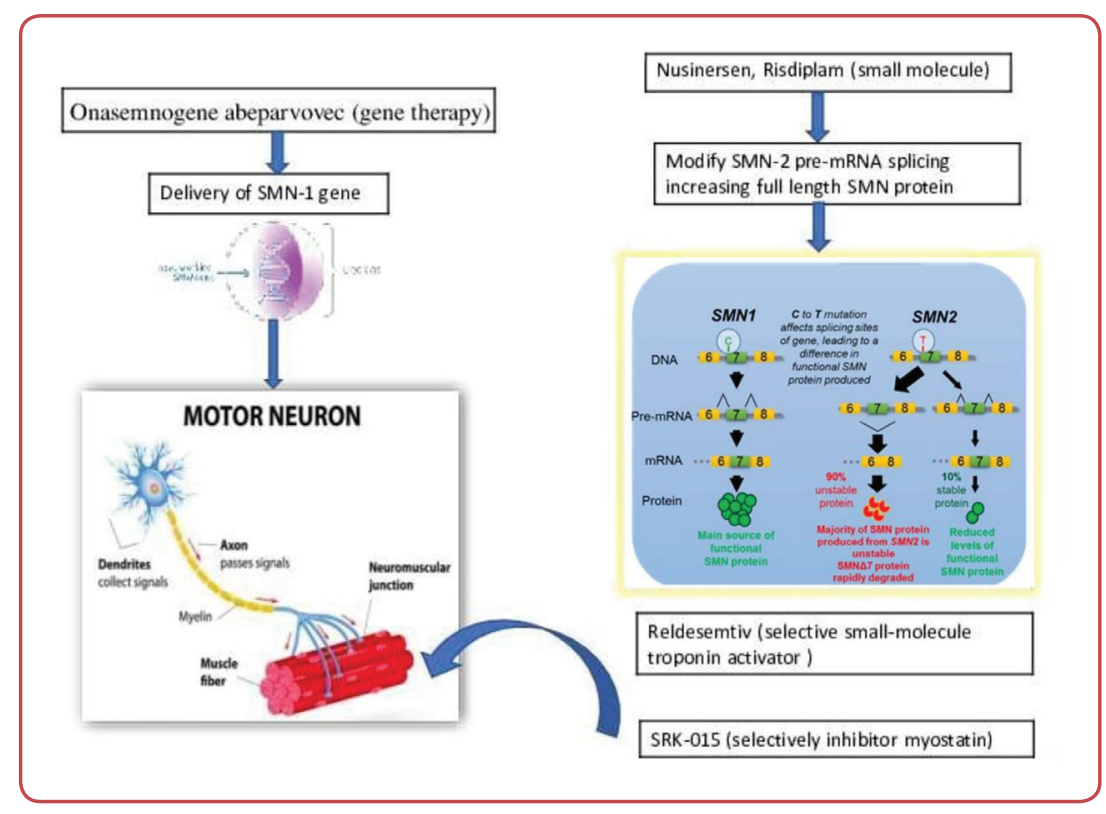

Figure 1: Core existing therapeutic options and their mechanism of action

SMN1 = Survival Motor Neuron 1; SMN2= Survival Motor Neuron 2; SMN = Survival Motor Neuron

\section{SMN gene insertion therapy}

\section{(a) Splicing modification of SMN-2 gene}

(i) Nusinersen is a disease modifying therapy established by Biogen (USA). It was first drug that was approved by the FDA for treatment in adults and children, as well as infants with SMA. ${ }^{15}$ The European Union approved nusinersen in June 2017 to treat SMA. Nowadays, nusinersen is available in 29 European countries for regular reimbursement. This drug is now approved in many other countries, including Australia, Canada, Japan, Israel and Turkey. It is administered into the central nervous system by intrathecal route. This drug has orphan status under orphan drug designation program in the United States and the European Union. ${ }^{16}$ This drug is structured as antisense oligonucleotide (ASO) in treatment of SMA that is occurred due to mutations in longer arm (q-). ${ }^{17}$

Nusinersen drug is an ASO. It corrects splicing of the SMN-2 gene. ${ }^{16}$ It increases exon-7 insertion in SMN-2 gene mRNA transcripts, which finally produces the full-length SMN protein. This was shown in animal experiment of in vitro assays and transgenic animal models of SMA's disease studies.

The plasma concentration of nusinersen is relatively low, compared to the lowest cerebrospinal fluid concentration. The maximum concentration of the drug in plasma after administration is after 1.7 - $6 \mathrm{~h} .{ }^{16}$ The drug is distributed from blood to cerebrospinal fluid and peripheral tissues (skeletal muscle, liver, kidney). It is metabolised through exonuclease enzyme (3'- and 5'-) mediated hydrolysis process and it does not act as a substrate for inhibitor, or inducer of cytochrome P-450 enzymes. Elimination half-life is 135-177 days in cerebrospinal fluid and 63-87 days in plasma. The drug primary elimination route is likely by urinary excretion. After $24 \mathrm{~h}$, only $0.5 \%$ of the administered drug amount was recovered in urine. Dose (in adults and children) is $12 \mathrm{mg}$ in $5 \mathrm{~mL}$, single dose, via intrathecal route administration. Initial 4 loading doses are required; first three doses at 14 days interval and the fourth dose is given 30 days after the third dose. The maintenance dose is one dose every 4 months.

Nusinersen approval was grounded on the ENDEAR clinical trial. Subsequently hopeful outcomes for nusinersen in phase 1 and 2 of clinical trials with SMA type-II and -III in children has led to phase 3 (randomised, double-blind, sham procedure controlled studies were started). ${ }^{19,}{ }^{20}$ ENDEAR (ClinicalTrials.gov identifier: NCT02193074, in year 2014 to 2016) evaluated safety and clinical efficiacy of nusinersen drug in 121 infant, with infantile onset SMA type earli- 
er than 7 month of age. CHERISH trial (ClinicalTrials.gov identifier: NCT02292537, year 2014 to 2017) included 126 children with late onset/adulthood type SMA. At baseline, the median age was 4 year (range 2-9 year) in treated patient's group and 3 year (2-7 year) in control group. NURTURE phase 2 (ClinicalTrials.gov identifier: NCT02386553, initiated in 2017) open-label, single arm, multinational study is ongoing.

(ii) Risdiplam is indicated for SMA-I, II and III type in adults and children aged 2 months or older. ${ }^{21}$ It is a first drug which is given orally. The drug was established associated with PTC Therapeutics and SMA Foundation and by Genentech company, a member of the Roche Group (USA). This drug is available as oral solution with maximal dose of 5 mg administered daily.

It is a mRNA splicing modifier for SMN-2 gene designed to treat SMA disease. ${ }^{21,}{ }^{22}$ Basically, it increases the inclusion of exon-7 throughout splicing process, which finally increase the quantity of functional SMN protein formed by SMN-2. The peak plasma time following the drug oral administration is 1-4 hours, followed by once-daily administration with a morning meal (or when breastfeeding), risdiplam reaches steady-state after 7-14 days. It is bounded to serum albumin protein, deprived of any binding to $\alpha-1$ acid glycoprotein, with $11 \%$ free fraction. The apparent volume of distribution at steady state is $6.3 \mathrm{~L} /$ $\mathrm{kg}$. Risdiplam is primary metabolised by ketone monooxygenase 1 and 3 (FMO-1 and FMO-3) and additionally by cytochromes: 1A1, 2J2, 3A4, and 3A7. Parent drug is the main element found in plasma, accounting for $83 \%$ of drug-related material in circulation. Elimination half-life is proximately $50 \mathrm{~h}$, clearance: $2.1 \mathrm{~L} / \mathrm{h}$ (for $14.9 \mathrm{~kg}$ patient). If the dose of $18 \mathrm{mg}$ of risdiplam is administered by oral route, around $53 \%$ of the dose is excreted by the faeces and $28 \%$ by urine. In child at the age of 2 months and above dose is 5 mg orally once a day for one year (Table 3). Most common adverse effects are fever, diarrhoea and rashes, sometimes oral and aphthous ulcers, joint pain and infection of urinary tract.

\section{Table 3 : Dose of risdiplam according to patient's age}

\begin{tabular}{|c|c|}
\hline Age & Dose \\
\hline Age $\geq 2$ months to $<2$ years & 0.2 mg/kg orally / once a day \\
\hline Age $\geq 2$ years and weight $<20 \mathrm{~kg}$ & $0.25 \mathrm{mg} / \mathrm{kg}$ orally / once a day \\
\hline Age $\geq 2$ years and weight $\geq 20 \mathrm{~kg}$ & 5 mg/kg orally / once a day \\
\hline
\end{tabular}

The approval of this drug by FDA was grounded on the outcomes from 2 clinical research studies: FIREFISH trial in infantile-onset SMA cases and SUNFISH trial in later-onset SMA cases. FIREFISH was an open-label type study, 2 parts pivotal clinical trial in infants aged from 2-7 months in SMA-I type. ${ }^{23}$ Results showed $41 \%$ (7/17) of these infants attained skill to sit without any support for at least five seconds and $90 \%$ (19/21) infants did not required permanent ventilation at 12 months of age. Later, after minimum duration of treatment of 23 months and reaching an age of 28 months or elder, $81 \%(17 / 21)$ of all children were alive without permanent ventilation. The SUNFISH study was a 2 part, double-blind, placebo controlled pivotal research trial in two-yearold children to 25 year old young adults of SMA-II and SMA-III. ${ }^{24}$ A clinically meaningful and statistically important development in motor function of muscle among children and adults was observed as measurement of a change from baseline in the MFM-32 total score. Improved upper extremities motor function as compared from baseline, as measured by the Revised Upper Limb Module (RULM), a secondary independent muscle motor function end point of the study, also showed statistically significant improvement.

Apart from FIREFISH and SUNFISH study, risdiplam was assessed in the wide-range of SMA cases, including in JEWELFISH study, an open-label exploratory clinical trial in SMA type I, II or III aged 6 months to 60 years who were earlier treated with SMA medications, gene replacement therapy / olesoxime. Recruitment was completed by enrolment of 174 patients. RAINBOWFISH study is an open-label, single-arm, multicentre research that investigate the efficacy, safety, pharmacodynamics and pharmacokinetics of risdiplam in babies (approximately 25 patients), from 0 to 6 weeks (at first dose) in patients whom SMA was diagnosed by genetically testing, while they were still without symptoms. The study is currently recruiting.

\section{(b) Gene replacement therapy}

Onasemnogene abeparvovec (earlier called as AVXS-101) is used as a SMN-1 gene replacement therapy medication. It is given in SMA-I type cases, to children aged two years or younger. ${ }^{25}$ The FDA approved this drug on 24 May 2019 for SMA. It is developed by the Swiss drug maker Novartis, under the trade name Zolgensma. 
It is recombinant adeno-associated virus (AAV9) based on gene replacement therapy medication that is created to carry a gene copy encoding the SMN protein. It is available as suspension form for intravenous infusion. It is provided as a kit that comprises 2-9 vials, with mixture of two vial fill volumes (both $5.5 \mathrm{~mL} / 8.3 \mathrm{~mL}$ ). Entirely vials contain nominal concentration of $2 \times 10^{13}$ vector genomes in $1 \mathrm{~mL}$. Separately vial covers an extractible volume of more than $5.5 \mathrm{~mL} / 8.3 \mathrm{~mL}$. There is no establishment of the safety and efficacy of drug for children aged 2 years and above. A single intravenous infusion is administered through a venous catheter that contains $1.1 \times 10^{14} / \mathrm{kg}$ vector genomes. Adverse reactions in $>10 \%$ cases is elevated aminotransferases ( $>$ ULN) $(27.3 \%)$ and in $1-10 \%$ cases vomiting (6.8\%).

Approval was supported by phase 1 of STR1VE trial, with still ongoing phase $3 .{ }^{26}$ In this trial, 15 SMA-I cases were enrolled, and received single dose of blood vessel adeno-associated virus serotype-9 carrying spinal muscular neuron corresponding deoxyribonucleotide encrypting the lost SMN protein. Out of 12 enrolled subjects, 11 could be seated without support, 9 set rolling over, 11 could take a meal orally, might speak and two have walked without any dependency. Four cases presented with elevated serum aminotransferase enzyme levels which was diminished by prednisolone. Phase 3 STR1VE trial is ongoing, interim data analysis showed that $95 \%$ of subjects were alive and event-free. The median age was 9.5 months, six in out of seven (86\%) subjects aged 0.5 months or elder persisting eventfree. Interim results also exhibited constant enhancement of muscle unit motor milestones (head upright hold, rolling over, unaided sitting).

\section{SMN non-dependent therapy}

Reldesemtiv is an advance drug which is taken orally, small molecule medication that is being established via Cytokinetics, with partnership of Astellas Pharma company, indicated for enhancement of function of skeletal muscles accompanying by neuro-muscular dysfunction, atrophy of muscles or decrease strength in SMA. It rapidly activates the skeletal muscle troponin, thus also called Fast skeletal troponin activator or FSTA. It is stimulant of troponin which is anticipated with the slow rate of calcium ion release from fast skeletal muscle fibre's regulatory troponin complex.${ }^{27}$ Subsequently, the Phase I study suggests confirmatory safety parameters. A Phase II, double-blind, randomised and placebo-controlled trial (ClinicalTrials.gov identifier: NCT02644668, years 2015-2018) on 70 cases SMA -II to -IV type observed its functional and respiratory performance related effects. The outcomes of the study are: in the group with higher doses, a drift towards an upsurge from baseline in the six-minute walk test (6-MWT) and of the maximal expiratory pressure (MEP). In between treated and placebo groups, there are similar adverse events reported.

A monoclonal antibody named SRK-015 selectively inhibits myostatin (also known as growth differentiation factor-8), endorsing muscle spindles growth and differentiation and improving muscle force in SMA cased mice. ${ }^{28}$ A first phase trial (ClinicalTrials.gov identifier: NCT02644777, years 2017-2018) confirmed its safety and tolerability. A second phase study (TOPAZ, ClinicalTrials.gov identifier: NCT03921528, started in 2019 and ongoing), involved 58 SMA-II and -III cases, aged 2-21 years. These have acknowledged therapy through intravenous infusion every 4 weeks for 1 year. The results of a six-month interim study were obtained by the end of year 2020 .

\section{Other therapy}

Valproic acid (VPA) is an anti-epileptic drug that has been used conventionally to treat patients with epilepsy. But recent research suggests that treatment with valproic acid and other drugs such as sodium phenylbutyrate, hydroxycarbamide and albuterol sulphate have been demonstrated to increase SMA transcription in laboratory findings. Apart from this, clinical research have not established markable development in disease progression. ${ }^{29}$ The SMA CARNIVAL trials parts 1 and 2 suggests that valproic acid and L-carnitine are ineffective in improvement of strength and functions at the children 6-12 months of age. ${ }^{30}$ Only $85 \%$ of total cases reported adverse effects. Gabapentin, olesoxime and riluzole medications are studied for their suspected neuroprotective properties, while not vital clinically profit was noted. Creatine, sodium phenylbutyrate, gabapentin, thyrotropin releasing hormone and hy- 
droxyureas medications used for SMA have conjointly well-tried ineffective.

\section{SMN non-dependent therapeutic goals in} reference to future prospective

In upcoming years autophagy inhibition could also be option available in treatment of SMA. Previously in vitro and in vivo studies regarding SMA have informed potential autophagic characteristics in SMA-cultured motor neurons, reporting about dysregulation of autophagy, which could help in decrease of progression of SMA. ${ }^{31}$ Autophagy is a significant intracellular process through which components of cytosol are transported by double-membrane vesicles, known as autophagosomes that are used for lysosomes to cell's degrading process. This process is extremely controlled via a sequence of proteins, that are known as autophagy-related genes (ATGs). Basically, autophagic pathways regulate degradation of cytoplasmic contents like damaged mitochondria, injured cytosolic organelles, attack pathogens and aggregate prone proteins.

Over the previous years, various spinal muscle neuron freelance factors are considered in pathophysiology of SMA, on the idea of in vitro and in vivo studies and consequently they might characterise forthcoming therapeutic goals. Besides, administration of injection via intramuscular route of brain derived neurotrophic factors and $\mathrm{C}$-fragment of the tetanus toxin heavy chain may decrease the activity of autophagy markers (Atg5,Becn1, Lc3 and p62) in transcript lacking of exon-7 muscles SMA mice deprived of effects on body mass and survival time. ${ }^{32}$ Moreover, arrestment of autophagy process by invasive injection technique of 3-methyladenine (3-MA) directly into cerebrospinal fluid in cerebral ventricles (to bye-pass the bold brain barrier) has been re- vealed to have better autophagic characteristic, prolong lifespan and recover motor performances in SMA pups. ${ }^{31}$ Numerous evidences suggest that apoptotic processes have been proved to have a role in SMA pathology. In vitro studies suggested SMN protein decline stimulates apoptosis. ${ }^{33}$ JNK-3 (c-Jun NH2-terminal kinase) cascades, identified as a pro-apoptotic role is triggered in transcript lacking exon-7 SMA mice and in SMA affected person. ${ }^{34}$ Additionally, c-Jun NH2-terminal kinase pharmacological inhibition improves morphological characteristic, recovers motor performances and life expectancy of SMA mice. ${ }^{18}$

\section{Current scenario for treatment of SMA dis- ease in Rajasthan}

In the month of September 2020, JK Loan Hospital, part of Sawai Man Singh Hospital Medical College and Attached Group of Hospital, had a visit from a 3-year-old child suffering from SMA from Gorakhpur City, Uttar Pradesh. The patient was brought to JK Lone Hospital in Jaipur for special treatment. When he was 8 months old, his mother noticed that child showed decreased movement and weakness in lower limbs. The child was unable to stand and walk. SMA was suspected and routine blood test, serum creatinine kinase test and electromyography were performed. Serum creatine kinase level was normal and in EMG, typically prominent fibrillation potential and markedly diminished compound action potential was found. As gold standard diagnostic method, genetic test confirmed SMA. He was treated by giving the first dose of the risdiplam drug. The best part of the treatment is that this drug is taken at home. However, pediatricians of JK Loan Hospital have asked the patient to come to the hospital every month for follow up so that they would be able to monitor his health and the muscle tone. The drug cost Rs 4 crores/year and it is to be giv-

Table 4 : Therapeutic options for the SMA patients

\begin{tabular}{|c|c|c|c|c|c|}
\hline $\begin{array}{l}\text { Therapeutic } \\
\text { option }\end{array}$ & $\begin{array}{l}\text { SMA } \\
\text { type }\end{array}$ & Mechanism of action & $\begin{array}{l}\text { Route of } \\
\text { administration }\end{array}$ & $\begin{array}{l}\text { Trial's } \\
\text { status }\end{array}$ & $\begin{array}{l}\text { FDA } \\
\text { Status }\end{array}$ \\
\hline Nusinersen & I, II, III & Antisense oligonucleotide & Intrathecal & I, II, III & Approved \\
\hline Risdiplam & I, II, III & Small molecule & Oral & I, II, ||| & Approved \\
\hline $\begin{array}{l}\text { Onasemnogene } \\
\text { abeparvosec }\end{array}$ & I, II & AAV-9-vector construct & Intravenous & I, II, III & Approved \\
\hline Reldesemtiv & II, III, IV & Fast activator skeletal troponin & Oral & I, II & Not approved \\
\hline SRK-105 & II, III & Myostatin inhibitor & Intravenous & I, II & Not approved \\
\hline Olesoxime & $\|\|$, & Anti-apoptotic agent & Oral & $\begin{array}{c}\text { I, II } \\
\text { (development } \\
\text { finished in 2018) }\end{array}$ & Not approved \\
\hline
\end{tabular}


en lifelong. The medicine was provided to the patient under the compassionate use programme. This medicine has been introduced to a patient for the second time in the country. This medicine can be given to children of all types of SMA free of charge due to the rarity of the disease. Most patients die prematurely due to respiratory failure. It is expected that after this treatment, the child will be able to live a normal life.

Treatmen options of SMA are profoundly varying and are given according to SMA's type and muscle atrophy progression. Summary of treatment options is presented in Table 4.

\section{Conclusion}

SMA is rare disease that can manifested at any period from intrauterine life to birth and adulthood with different severity. To diagnose this disease, doctors are facing many difficulties because there is not enough information, relevant literature and genetic analysis. Therapeutic options for now cannot recover motor neurons or muscle spindle cells which were previously lost, but they can still delay the progression of muscle atrophy, control the severity of the disease and help recover a person's permanent muscle function. Goal is to improve quality of life as well as better life expectancy. Some above given therapeutic options are now available and they help reduce disease progression, give patient better quality of life and decrease mortality. It is expected that the scope of therapeutics option will increase gradually even further, and patients will get relief from this disease completely.

\section{Acknowledgements}

None.

\section{Conflict of interest}

None.

\section{References}

1. Werdnig G. Two early infantile hereditary cases of progressive muscular atrophy simulating dystrophy, but on a neural basis. Arch Neurol 1971 Sep;25(3):276-8.

2. Hoffmann J. "Uber" chronische spinale Muskelatrophie im Kindesalter, auf familiärer Basis. [On chronic spinal muscular atrophy in childhood, with a familial basis]. Dtsch Z Nervenheilkd 1893(3):427-70. German.

3. Kolb SJ, Kissel JT. Spinal muscular atrophy. Neurol Clin 2015 Nov;33(4):831-46.

4. Ogino S, Leonard DG, Rennert H, Ewens WJ, Wilson RB. Genetic risk assessment in carrier testing for spinal muscular atrophy. Am J Med Genet 2002 Jul 15;110(4):301-7.

5. Prior TW, Snyder PJ, Rink BD, Pearl DK, Pyatt RE, Mihal DC, et al. Newborn and carrier screening for spinal muscular atrophy. Am J Med Genet A 2010 Jul;152A(7):1608-16.

6. Munsat TL, Davies KE. International SMA consortium meeting. (26-28 June 1992, Bonn, Germany). Neuromuscul Disord 1992;2(5-6):423-8.

7. Spinal muscular atrophy [Internet] [Cited 23-Mar-2021]. Available from: www.medicalnewstoday.com.

8. Butchbach ME. Copy number variations in the survival motor neuron genes: implications for spinal muscular atrophy and other neurodegenerative diseases. Front Mol Biosci 2016 Mar 10;3:7.

9. Arnold WD, Kassar D, Kissel JT. Spinal muscular atrophy: diagnosis and management in a new therapeutic era. Muscle Nerve 2015 Feb;51(2):157-67.

10. Main M, Kairon H, Mercuri E, Muntoni F. The Hammersmith functional motor scale for children with spinal muscular atrophy: a scale to test ability and monitor progress in children with limited ambulation. Eur J Paediatr Neurol 2003;7(4):155-9.

11. Krosschell KJ, Maczulski JA, Crawford TO, Scott C, Swoboda KJ. A modified Hammersmith functional motor scale for use in multi-center research on spinal muscular atrophy. Neuromuscul Disord 2006 Jul;16(7):417-26.

12. O'Hagen JM, Glanzman AM, McDermott MP, Ryan PA, Flickinger J, Quigley J, et al. An expanded version of the Hammersmith Functional Motor Scale for SMA II and III patients. Neuromuscul Disord 2007 Oct;17(9-10):693-7.

13. Glanzman AM, O'Hagen JM, McDermott MP, Martens WB, Flickinger J, Riley S, et al; Pediatric Neuromuscular Clinical Research Network for Spinal Muscular Atrophy (PNCR); Muscle Study Group (MSG). Validation of the Expanded Hammersmith Functional Motor Scale in spinal muscular atrophy type II and III. J Child Neurol 2011 Dec;26(12):1499-507.

14. Lorson CL, Rindt H, Shababi M. Spinal muscular atrophy: mechanisms and therapeutic strategies. Hum Mol Genet 2010 Apr 15;19(R1):R111-8.

15. SPINRAZA- nusinersen injection, solution. DailyMed, 30 June 2020. [Internet][Accesed: 3-Nov-2020]. Available at: https://dailymed.nlm.nih.gov/dailymed/drugInfo.cfm?setid $=$ dd $70 \mathrm{~cd} 5 \mathrm{f}-\mathrm{b} 0 \mathrm{fc}-4 \mathrm{ba} 4-\mathrm{a} 5 \mathrm{ea}-89 \mathrm{a} 34778 \mathrm{~b}-$ d94\#: :text=SPINRAZA\%20is $\% 20$ indicated $\% 20$ for $\% 20$ the,in\%20pediatric\%20and\%20adult\%20patients.

16. Specialist Pharmacy Service. Nusinersen, 2016. [Internet] [Accesed: 3-Nov-2020]. Available at: https://www.sps. nhs.uk/medicines/nusinersen/.

17. Paton DM. Nusinersen: antisense oligonucleotide to increase SMN protein production in spinal muscular atrophy. Drugs Today (Barc) 2017 Jun;53(6):327-37.

18. Schellino R, Boido M, Borsello T, Vercelli A. Pharmacological c-Jun NH2-terminal kinase (JNK) pathway inhibition 
reduces severity of spinal muscular atrophy disease in mice. Front Mol Neurosci 2018 Sep 4;11:308.

19. Chiriboga CA, Swoboda KJ, Darras BT, Iannaccone ST, Montes J, De Vivo DC, et al. Results from a phase 1 study of nusinersen (ISIS-SMN(Rx)) in children with spinal muscular atrophy. Neurology 2016 Mar 8;86(10):890-7.

20. Finkel RS, Chiriboga CA, Vajsar J, Day JW, Montes J, De Vivo DC, et al. Treatment of infantile-onset spinal muscular atrophy with nusinersen: a phase 2 , open-label, dose-escalation study. Lancet 2016 Dec 17;388(10063):3017-26.

21. The U.S. Food and Drug Administration. FDA approves oral treatment for spinal muscular atrophy, 7 August 2020. [Internet][Accesed: 3-Nov-2020]. Available at: https://www.fda.gov/news-events/press-announcements/fda-approves-oral-treatment-spinal-muscular-atrophy.

22. Sturm S, Günther A, Jaber B, Jordan P, Al Kotbi N, Parkar $\mathrm{N}$, et al. A phase 1 healthy male volunteer single escalating dose study of the pharmacokinetics and pharmacodynamics of risdiplam (RG7916, R07034067), a SMN2 splicing modifier. Br J Clin Pharmacol 2019 Jan;85(1):181-93.

23. Baranello G, Servais L, Day JW, Deconinck N, Mercuri $\mathrm{E}$, Klein A, et al. FIREFISH part 1: 1-year results on motor function in babies with type 1 SMA. Neurology 2019 Apr;92(15):S25.003.

24. Mercuri E, Barisic N, Boespflug-Tanguy O, Deconinck N, Kostera-Pruszczyk A, Masson R, et al. SUNFISH Part 2: Efficacy and safety of risdiplam (RG7916) in patients with Type 2 or non-ambulant Type 3 spinal muscular atrophy (SMA). Neurology 2020 Apr;94(15):1260.

25. Le TT, McGovern VL, Alwine IE, Wang X, Massoni-Laporte A, Rich MM, et al. Temporal requirement for high SMN expression in SMA mice. Hum Mol Genet 2011 Sep 15;20(18):3578-91.

26. Day JD, Chiriboga CA, Crawford TO, Darras BT, Finkel RS, Connolly AM, et al. Onasemnogene Abeparvovec-xioi gene-replacement therapy for spinal muscular atrophy type 1 (SMA1): Phase 3 US study (STR1VE) Update. Neurology $2020 \mathrm{Apr} ; 94(15): 1828$.
27. Hwee DT, Kennedy A, Ryans J, Russell AJ, Jia Z, Hinken AC, et al. Fast skeletal muscle troponin activator tirasemtiv increases muscle function and performance in the B6SJL-SOD1G93A ALS mouse model. PLoS One 2014 May 7;9(5):e96921.

28. Feng Z, Ling KK, Zhao X, Zhou C, Karp G, Welch EM, et al. Pharmacologically induced mouse model of adult spinal muscular atrophy to evaluate effectiveness of therapeutics after disease onset. Hum Mol Genet 2016 Mar 1;25(5):964-75.

29. Tsai LK, Tsai MS, Ting CH, Li H. Multiple therapeutic effects of valproic acid in spinal muscular atrophy model mice. J Mol Med 2008;86:1243-54.

30. Swoboda KJ, Scott CB, Crawford TO, Simard LR, Reyna SP, Krosschell KJ, et al; Project Cure Spinal Muscular Atrophy Investigators Network. SMA CARNI-VAL trial part I: double-blind, randomized, placebo-controlled trial of L-carnitine and valproic acid in spinal muscular atrophy. PLoS One 2010 Aug 19;5(8):e12140.

31. Piras A, Boido M. Autophagy inhibition: a new therapeutic target in spinal muscular atrophy. Neural Regen Res 2018 May;13(5):813-4.

32. Oliván S, Calvo AC, Rando A, Herrando-Grabulosa M, Manzano R, Zaragoza P, et al. Neuroprotective effect of non-viral gene therapy treatment based on tetanus toxin C-fragment in a severe mouse model of spinal muscular atrophy. Front Mol Neurosci 2016 Aug 24;9:76.

33. Parker GC, Li X, Anguelov RA, Toth G, Cristescu A, Acsadi G. Survival motor neuron protein regulates apoptosis in an in vitro model of spinal muscular atrophy. Neurotox Res 2008 Jan;13(1):39-48.

34. Genabai NK, Ahmad S, Zhang Z, Jiang X, Gabaldon CA, Gangwani L. Genetic inhibition of JNK3 ameliorates spinal muscular atrophy. Hum Mol Genet 2015 Dec 15;24(24):6986-7004. 